\title{
KONSEP DAKWAH BIL HAL DALAM MAJELIS TAKLIM \\ DI MASJID AL-AMINIYAH SUDIMARA PINANG KOTA TANGERANG
}

\author{
Khaisar Masrul ${ }^{1}$; Ahmad Saiful Bahri ${ }^{2}$ \\ Universitas Islam Negeri (UIN) Syarif Hidayatullah Jakarta \\ E-mail: cmasrul@gmail.com ${ }^{1}$; asbsaiful99@gmail.com ${ }^{2}$
}

\begin{abstract}
Abstrak
Konsep dakwah Bil Hal dalam majelis taklim di masjid Al-aminiyah Sudimara Pinang Kota Tangerang. Dalam konteks tersebut. Penulis bermaksud menjawab pertanyaan dasar bagaimana pelaksanaan konsep dakwah tersebut dilaksanakan. Lebih spesifiknya penulis akan mengkaji tiga pertanyaan pertama, bagaimana histori yang memengaruhi jamaah tersebut terhalang shalat Isya' diawal waktu. Kedua, apa yang mendasari tujuan identitas politik dan pluralism kritis dalam majelis tersebut. Ketiga, bagaimana pandangan serta efek dari ceramah tersebut kepada para jamaah. Pada the media student's book fifth edition Gill Branston and Roy Stafford tahun 2010. Penulis akan menganalisis dengan tiga konsep dalam buku tersebut. Konsep yaitu setelah marxism, identitas politik dan pluralism kritits dan ceramah. Pada analisanya telah menjawab tiga pertanyaan minor. Kesadaran dalam diri muslim meningkatkan keilmuan dan ibadah amaliyah. Dalam simpulan pada makalah ini dapat dikemukakan hal-hal berikut: pertama, Islam adalah agama dakwah. Kedua, Islam menyatukan manusia secara sosial dan mewujudkan masyarakat bermartabat (Khaira Ummah). Ketiga, tidak menyia-nyiakan waktu dalam shalat Fardhu. Keempat, berpengetahuan agama juga memiliki kecerdasan kultural. Kelima, mengerjakan yang ma'ruf dan meninggalkan yang mungkar.
\end{abstract}

Kata Kunci: Dakwah Bil Hal, Majelis Taklim, Pluralism, Ceramah.

\begin{abstract}
The concept of da'wah Bil Hal in the taklim assembly in the mosque al-aminiyah Sudimara Pinang Tangerang City. In that context. The author intends to answer the basic question of how the implementation of the concept of da'wah is implemented. More specifically, the author will examine the first three questions, how the history that affects the congregation is hindered by 'Isha' prayer at the beginning of time. Second, what underlies the objectives of political identity and critical pluralism in the assembly. Third, how the views and effects of the talk were to the worshippers. In the media student's book fifth edition Gill Branston and Roy Stafford in 2010. The author will analyze with three concepts in the book. The concept is after Marxism, identity politics and pluralism kritits and lectures. In his analysis has answered three minor questions. Awareness in Muslims increases the science and worship of amaliyah. In conclusion in this paper can be put forward the following: first, Islam is the religion of da'wah. Second, Islam unites people socially and realizes a dignified society (Khaira Ummah). Third, do not waste time in praying
\end{abstract}


Fardhu. Fourth, knowledgeable religion also has cultural intelligence. Fifth, do the righteous and leave the evil.

Keyword: Da'wah Bil Hal, Assembly taklim, Pluralism, Lectures.

\section{PENDAHULUAN}

Majelis taklim berasal dari dua suku kata, yaitu kata majelis dan kata taklim. Dalam bahasa Arab kata majelis adalah bentuk isim makan (kata tempat) kata kerja dari jalasa yang artinya tempat duduk, tempat sidang, dewan. ${ }^{1}$ Dakwah bil hal adalah bentuk ajakan kepada Islam dalam bentuk amal, kerja nyata, baik yang sifatnya seperti mendirikan lembaga pendidikan Islam, kerja bakti, mendirikan bangunan keagamaan, penyantunan masyarakat secara ekonomis, kesehatan atau bahkan acara-acara hiburan keagamaan. ${ }^{2}$ Konsep dakwah bil hal dalam majelis taklim di masjid Al-Aminiyah Sudimara Pinang Kota Tangerang merupakan rutinitas yang dilaksanakan setiap hari Senin s.d Kamis pukul 18.30 19.30 WIB yang dihadiri oleh masyarakat setempat yang notabene berada disekitar masjid tersebut. Implikasi dari pernyataan Islam sebagai agama dakwah menuntut umatnya agar selalu menyampaikan dakwah, karena kegiatan ini merupakan aktifitas yang tidak pernah usai selama kehidupan dunia masih berlangsung dan akan terus melekat dalam situasi dan kondisi apapun bentuk dan coraknya. ${ }^{3}$

Hakikat dakwah adalah menyeru kepada manusia untuk menuju kepada jalan kebaikan, memerintahkan yang ma'ruf dan memcegah yang munkar dalam memperoleh kebahagiaan di dunia dan kesejahteraan di akhirat. ${ }^{4}$ Berdakwah memang dibutuhkan ketangguhan dan kekuatan, hingga ajaran agama tidak tersiasiakan dan mencelakakan manusia. Sebab hakikat dakwah adalah membina dan mempersatukan umat manusia, serta menyelamatkan merekadari kesengsaraan dunia dan akhirat. ${ }^{5}$ Selanjutnya salah satu aktivitas keagamaan yang secara langsung digunakan untuk mensosialisasikan ajaran Islam bagi penganutnya dan

\footnotetext{
${ }^{1}$ Ahmad Warson Munawir, AL-Munawir: Kamus Bahasa Indonesia (Cet. 4; Yogyakarta: Pustaka Progresif, 2008), 202.

2 Samsul Munir Amin, Ilmu Dakwah, (Jakarta: Amzah, 2009), 178.

${ }^{3}$ Munzir Supata, \& Harjani Hefni, Metode Dakwah, (Jakarta: Prenada Media, 2003), 5.

${ }^{4}$ Said bin Ali bin wahf al-Qahtani, 9 Pilar Keberhasilan Da'i Di Medan Dakwah, Diterjemahkan; Muzaidi Hazbullah, (Solo; Pustaka Arafah, 2001), 11.

${ }^{5}$ Ahmad Mudjab Mahalli, Buku Pintar Da'i, (Surabaya: Duta Ilmu, 2005), 6.
} 
umat manusia pada umumnya adalah aktivitas dakwah. Akitivitas ini dilakukan baik melalui lisan, tulisan, maupun perbuatan nyata. ${ }^{6}$ Sesuai dengan firman Allah SWT dalam QS At-Taubah/9: 71. Sebagai berikut:

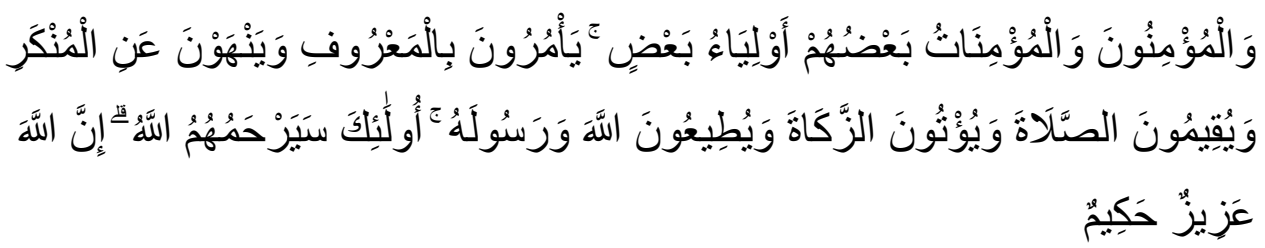

Terjemahnya: "Dan orang-orang yang beriman laki-laki dan perempuan, sebagian mereka (adalah) menjadi penolong bagi sebagian yang lain. Mereka menyuruh (mengerjakan) yang ma'ruf dan mencegah dari yang mungkar". 7

Dalam penerapannya konsep dakwah bil hal dalam masjelis taklim di masjid tersebut sudah benar sesuai dengan tuntunan yang diajarakan, kitab yang digunakan dalam kegiatan juga bervariasi yang pernah penulis dengar yaitu kitab Imam Nawawi Syarah Dan Terjemah Riyadhus Shalihin jilid 1 yang dikitab tersebut terdapat banyak aspek kehidupan guna peningkatan ibadah amaliyah bagi para jamaah yang hadir. Sejarah budaya manusia telah membuktikan betapa besar potensi manusia. Suatu bangsa yang tidak mampu atau mengabaikan pengembangan kemampuan manusia secara efektif, dengan sendirinya akan kurang mampu membangun dan mengembangkan masyarakat. ${ }^{8}$ Efektif atau tidaknya suatu metode dakwah sangat bergantung beberapa hal yang melingkupinya baik prinsip-prinsip penggunaan, metode atau juga faktorfaktor yang mempengaruhi pemikiran dan penggunaan metode tersebut.

Dakwah mengandung pengertian suatu kegiatan ajakan baik dalam bentuk lisan, tulisan tingkah laku dan sebagainya yang dilakukan secara sadar dan berencana dalam usaha mempengaruhi orang lain baik secara individual maupun secara kelompok tanpa adanya unsur-unsur paksaan. ${ }^{9}$ Dengan demikian jamaah majelis taklim dapat memberikan sumbangsi yang berharga bagi masyarakat di

${ }^{6}$ M. Munir, Wahyu Ilaihi, Manajemen Dakwah (Jakarta: Kencana, 2006), hal. 1.

7 Siregar. H. Imran dan Shofiuddin, Pendidikan Agama Luar Sekolah (Studi Tentang Majelis Taklim) (Jakarta: 2003), 16. 2001), 159

${ }^{8}$ Agus Safei dan Nanih Machendrawaty, Pengembangan Masyarakat Islam, (Bandung:

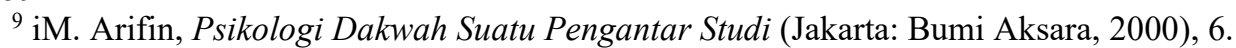


masa yang akan datang karena globalisasi merupakan keharusan sejarah umat manusia, seiring dengan perkembangan teknologi dan kemajuan ilmu pengetahuan dewasa ini. ${ }^{10}$

\section{PEMBAHASAN}

\section{A. Landasan Teoritis}

Dakwah bil al-hal adalah dakwah dengan perbuatan nyata seperti yang dilakukan oleh Rasulullah Saw, terbukti bahwa pertama kali tiba di Madinah yang dilakukan adalah Pembangunan masjid Quba, mempersatukan kaum Anshor dan Muhajirin dalam ikatan ukhuwah Islamiyah. ${ }^{11}$ Dakwah bil hal merupakan aktivitas dakwah islam yang dilakukan dengan tindakan nyata atau amal nyata terhadap kebutuhan penerima dakwah. Sehingga tindakan nyata tersebut sesuai dengan apa yang dibutuhkan oleh penerima dakwah. ${ }^{12}$ Al-Qur'an menyebutkan kegiatan dakwah dengan "Ashanulqaul Wal Haal” (ucapan dan perbuatan yang baik). Sebagaimana firman Allah SWT dalam surat Fushilat ayat 33, sebagai berikut:

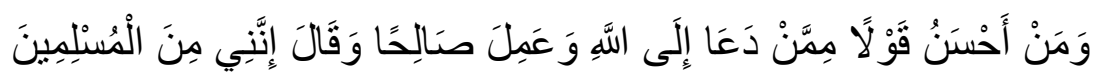

Terjemahan: "Siapakah yang paling baik perkataannya dripada orang yang menyeru kepada Allah, mengerjakan amal shaleh, dan berkata: "Sesungguhnya aku termasuk orang-orang yang menyerah diri."13

Dakwah bi al-hal yaitu dakwah dengan perbuatan nyata yang meliputi keteladanan. Misalnya dengan tindakan amal karya nyata yang dari karya nyata tersebut hasilnya dapat dirasakan secara konkret oleh masyarakat sebagai objek dakwah. ${ }^{14}$ Dakwah bi al-hal dilakukan oleh Rasulullah, terbukti bahwa ketika pertama kali tiba di Madinah yang dilakukan Nabi yaitu membangun masjid AlQuba, mempersatukan kaum Anshor dan Muhajirin. Kedua hal ini merupakan dakwah nyata yang dilakukan oleh Nabi yang dapat dikatakan sebagai dakwah bi al-hal. Dalam menganalisis konsep Dakwah Bil Hal pada majelis Taklim di Masjid

${ }^{10}$ Anonim, Pedoman iPembinaan Majelis Taklim (Jakarta: Dirjen Bimas Islam dan iUrusan Haji proyek iPeningkatan Tenaga iKeagamaan, 1995i), 6.

${ }^{11}$ Siti Muru'ah, Metodologi Dakwah Kontemporer. (Yogyakarta: Mitra Pustaka, 2000), 75.

${ }^{12}$ Samsul Munir, Ilmu Dakwah, (Jakarta: Amzah, 2009), 178.

13 "Metode Dakwah Bil Hikmah dan Bil Hal. BAB I", dalam tanjung bunut.blogspot.com/metode-dakwah-bil-hikmah-dan-bil-hal. (05, April 2017)

14 iSamsul Munir iAmin, illmu Dakwah, (Jakarta: iAmzah, i2009), i11. 
Al-Aminiyah Sudimara Pinang Kota Tangerang, Gill Branston With Roy Stafford mengemukakan lima aspek yaitu: 'Ideology' and its histories: Marxist approaches, Post-Marxism, Identity politics and critical pluralism, Discourses, Lived cultures. ${ }^{15}$ Dalam makalah ini akan menganalisis konsep dakwah bil hal dalam majelis taklim dimasjid Al-Aminiyah Sudimara Pinang Kota Tangerang dengan menggunakan Tiga Aspek Post-Marxism, Identity politics and critical pluralism, Discourses.

\section{Post-Marxism}

Several historical changes have affected the power of 'classic' Marxist theories:

a) The collapse of Eastern bloc state socialism from 1989 was disturbing for those who thought those countries had put Marxist ideas into action.

b) The renewed power of 'free market' or 'neoliberal' emphases and policies, from the 1970s, has permeated most areas of life. These arguably have their media theory equivalent: a tendency simply to celebrate audiences' powers in relation to media, as though corporate media were not in question, and the limits they set to the variety of media output, and to audiences' activities, on-or offline.

c) Equally influential have been some so-called postmodern positions. Despite their emphasis on 'deconstructing' dominant ideologies, they often seem to have constructed their own: an abandonment of any political connections to help construct a better world. A growing scepticism about the claims of science or reason to possess absolute truth, or to involve necessarily benign consequences for the world. This has enriched some areas of media analysis, especially of fictional forms. But it mattered for Marxism, which had claimed scientific status for its theories. ${ }^{16}$

15 Branston Gill With Roy Stafford, "The Media Student's Fifth Edition" (USA And CANADA, 2010), XI.

${ }^{16}$ Branston Gill With Roy Stafford, 180. 
Such changes resulted in key questions being asked, though arguably the strengths as well as the weaknesses of Marxism were lost when it was abandoned as an approach.

1) To talk of just one dominant ideology, directly related to economic power, implies an improbably argument-free ruling class, which is able smoothly to 'make' the rest of us go along with its interests. We're talking of capitalism here, rooted in competition and certain kinds of contradiction. Such 'single ideology' approaches often make very patronising assumptions about anyone other than the person doing the analysing. If the wheels of ideology roll so smoothly to produce conformity, how has the person analysing their workings come to have his or her 'outsider' perceptions?

2) The challenge of newer politics has offered ways of analysing other kinds of oppression. These are based in the ways that gender or ethnicity, for example, crucially affects 'life chances'. They are not seen as absolute determinants, as class was in the Marxist model. And there are important debates now about the difference between 'diversity' and 'inequality'. ${ }^{17}$

Dalam hal tersebut di atas, aspek Post - Marxism lebih mengedepankan hal pendekatan yang menganalisi secara liberal tidak mendekontruksikan ideology dominan dari marxis, Pandangan Marxisme sangat bertolak belakang dengan konsep Islam. Islam tidak pernah membedakan kelas pekerja atau majikan, dan kaya atau miskin. Orang miskin juga diharamkan bekerja sama untuk menghancurkan orang kaya (borjuis) atas nama perjuangan kelas. Kemunculan Ikhwanul Muslim di Mesir pada tahun 1928, Gerakan Jihad Islam di Palestina tahun 1960, Jamati Islami Pakistan tahun 1941, Masyumi di Indonesia tahun 1945, PAS Malaysia tahun 1951, Hizbulloh di Lebanon 1982, Partai Rafah di Turki 1981, dan berbagai gerakan sosial Islam lainnya di sejumlah negara secara umum merupakan manifestasi dari perubahan sosial dan struktur peluang politik

\footnotetext{
${ }^{17}$ Branston Gill With Roy Stafford, loc. cit.
} 
yang berimplikasi pada perubahan struktur politik internasional. ${ }^{18}$ Struktur peluang politik bisa diperoleh dari berbagai sumber, termasuk dari dunia internasional. Sebagai contoh sederhana yang menegaskan masalah ini adalah tumbuh dan berkembangnya gerakan-gerakan sosial Islam Indonesia pasca Orde Baru yang memanfaatkan struktur peluang politik dibuka dan diinisiasi oleh kaum kapitalis, meski dalam kenyataannya, kaum islamis mempersoalkan kapitalisme dan varian-variannya. ${ }^{19}$

Pembangunan dan perubahan masyarakat bisa melalui da'i yang menjadi agen perubahannya (agent of change) karena action (perbuatan nyata/perilaku) atau akhlaq da'i akan ditiru oleh umat (jamaah), Ada juga yang menyebut bahwa dakwah bil-hal adalah kegiatan dakwah yang dilakukan dengan memberi bantuan material atau non material. Bahkan ada yang menyebut bahwa dakwah melalui tulisan dan kreativitas tangan juga merupakan salah satu bentuk dakwah bil-hal. ${ }^{20}$ Menurut M. Natsir dakwah adalah usaha-usaha menyerukan dan menyampaikan kepada perorangan manusia dan seluruh umat manusia konsepsi Islam tentang pandangan dan tujuan hidup manusia di dunia ini, dan yang meliputi al-amar bi al-ma'ruf an-nahyu an al-munkar dengan berbagai macam cara dan media yang diperbolehkan akhlak dan membimbing pengalamannya dalam perikehidupan bermasyarakat dan perikehidupan bernegara. ${ }^{21}$

\section{Identity Politics and Critical Pluralism}

Some would argue that too much of Marxism's key interest in class differences has been lost in 'identity' emphases. We still live in deeply unequal capitalist societies, driven by profit, high consumption and gross inequalities. But these now operate on a global scale, with relations of

${ }^{18}$ iSyarifuddin Jurdi, “Gerakan Sosial Islam” Jurnal PolitikiProfetik Vol. 1. No. 1, i2013,i3.

${ }^{19}$ Lihat imisalnya Quintan iWiktorowics (ed.), Islamics iActivismei: A iiSocial Movement iTheory iApproach (Bloomington i\& Indianapolis: indiana University iPressi, 2004), iterjemahan iGerakan Sosial ilslam (Yogyakarta: Daging PusblishingidaniYayasan Wakaf iParamadina, 2012i); Noorhaidi iHasan, Laskar iJihad, Islam, Militancy, and ithe iQuest ifpr Identity iin iPost-iNew Order Indonesia (Ithaca, New York: Cornell University, 2006), terjemahan Laskar Jihad (Jakarta: LP3ES, 2008)

20 Alhadharah, “Dakwah Bil-Hal: Prospek Dan Tantangan Da'I” Jurnal Ilmu Dakwah Vol.14 No.27, 2015,18.

${ }^{21}$ M. Natsir, "Fungsi iDakwah iiPerjuangan” iDalam iAbdul iMunir iMulkhan, Ideologis Gerakan iDakwah, (Yogyakarta: Sipres, 1996), 52. 
exploitation spread across and between continents, and with other kinds of oppression also producing deprivations. ${ }^{22}$

Agama dalam identitas merupakan penanda bahwa eksistensi agama sebagai katalisator kehidupan manusia itu jelas sangat berarti. Seluruh agama memiliki aturan jelas serta orientasi dan perilaku dalam menjalankan agama pun sudah ditetapkan. Artinya agama mempolarisasikan individu sesuai tujuan agama itu sendiri. ${ }^{23}$

Pluralist models of media ownership have developed, seeing the media as floating free of power, and emphasising the apparent diversity and choice of media forms and products. They argue that, if certain values, or forms, are dominant, it is because they are 'genuinely popular' and have won out in this 'free market of ideas'. Time and again, for example, the 'popularity' of US cultural forms is attributed to 'universal' appeal rather than globally orchestrated power. ${ }^{24}$

Pembelokan warna tersebut, menurut Mun'im A. Sirry, terjadi karena keterbatasan manusia dalam mempersepsikan Tuhan Yang Absolut. Yang relatif tidak bisa menangkap Yang Absolut secara mutlak, kecuali sebatas kerelatifannya. Ini kaidah yang dipegang erat pendukung gagasan pluralisme agama. Alasannya, karena manusia yang secara ontologis relatif mustahil mampu mempersepsikan Tuhan Yang Maha Mutlak. Perbedaan ontologis itu memastikan adanya ‘jarak’ yang amat jauh antara manusia dan Tuhan. Menurut Sirry, jarak itu hanya bisa dimediasi melalui simbol-simbol sehingga manusia menangkapnya seolah-olah ada beragam bentuk Tuhan. Di titik inilah Komaruddin Hidayat menganggap terlalu sombong bila ada orang yang mengaku paham dan kenal Tuhan. Keterbatasan manusia sebagai makhluk yang relatif dalam mempersepsikan Yang Absolut itu seringkali mereka tamsilkan dengan cerita perbedaan persepsi tiga orang buta terhadap seekor gajah yang sama. ${ }^{25}$

22 Branston Gill With Roy Stafford, "The Media Student's Fifth Edition" (USA And CANADA, 2010), 184.

${ }^{23}$ M Chairul Basrun Umanailo, "AGAMA DALAM IDENTITAS” https://www.researchgate.net/publication/323943107 AGAMA DALAM IDENTITAS (diakses pada 30 November 2019, pukul 13.55 WIB)

${ }^{24}$ Ibid., 185.

${ }^{25}$ Ahmad Khoirul Fata “Diskursus dan Kritik Terhadap Teologi Pluralisme Agama” Jurnal MIQOT Vol. XLII No. 1, 2018, 13. 
Of course there is diversity in media, especially in an internet/interactive age. Both website owners and big corporations are driven to circulate many different ideas and identities to remain profitable. But we still need an account of power to understand how some ideas and imaginings came to circulate more freely than others. Thus, developing the original Marxist and Gramscian emphases, others (e.g. Thompson 1997) suggest we now live in times of a complex play between several kinds of power:

a) Economic power

b) Political power

c) Coercive, especially military, power (see Klein 2007 on the 'shock doctrine')

d) 'Symbolic power', i.e. the means of information and communication, including religions, schools, universities and, crucially, the media.

Such approaches are sometimes called critical pluralism. They acknowledge that there may be a struggle between competing discourses or accounts of the world, but insist that this is not an amicable 'level playing field' free-for-all. Some discourses are parts of powerful institutions and have easy access to credibility, material resources, legal power, publicity: access which will be fought for if necessary. Others are routinely marginalized. ${ }^{26}$ Maka dalam hal ini islam tidak lagi ingin dibawa pada periode nabi, tapi Islam dalam pandangan identitas politik umat, ialah melalui arus zaman, dan ikut dalam perubahan zaman, tapi subtansi ke-islaman yang tetap terjaga.

\section{Discourses}

'Discourse', as a concept in media studies, now often explores the 'struggle for meaning' at the level of words chosen for news reports, the phrasings of interview questions, the 'rules of the game'such as the 'language-etiquette, speech-tact and other forms of associating an utterance to the hierarchical organisation of society' (Frow in Bennettet al. 2005: 92). Discourse analysis explores what values and identities are contained, prevented or encouraged by the day-in, day-out practices and

\footnotetext{
${ }^{26}$ Gill Branston With Roy Stafford, op. cit. 185.
} 
(oftenunspoken) rules of a particular discursive formation, in Foucault's term. ${ }^{27}$

Langkah Sedangkan menurut A. G. Lugandi, ceramah agama adalah suatu penyampaian informasi yang bersifat searah, yakni dari penceramah kepada hadirin. ${ }^{28}$ Ceramah merupakan suatu teknik dakwah yang banyak diwarnai oleh ciri-ciri karakteristik bicara oleh seorang da'i pada suatu aktivitas dakwah. Metode ini harus diimbangi dengan kepandaian khusus tentang retorika, diskusi, dan faktor-faktor lain yang membuat pendengar merasa simpatik dengan ceramahnya. $^{29}$

\section{B. Metodologi}

\section{Takwa}

Islam menganjurkan peningkatan kesadaran beragama kepada yang kaya dengan reward dan punishment, bukan dengan menghancurkannya. Setiap manusia akan mendapatkan catatan amal di akhirat nanti. Ada yang menerima di sebelah kiri karena perbuatan baiknya lebih banyak dan ada pula yang menerima dari sebelah kiri karena kejahatannya. Bagi mereka yang menerima dari sebelah kiri akan dimasukkan kedalam api neraka yang bernyala-nyala. Setelah itu ia dililit rantai yang panjangnya tujuh puluh hasta yang menjadi penyebabnya demikian adalah karena ia tidak beriman kepada Allah dan tidak mau mendorong orang lain untuk memberi makan orang miskin. ${ }^{30}$ Ancaman lain yang dinyatakan Allah dalam firmanNya adalah mengkategorikan orang yang tidak menganjurkan memberi makan orang miskin ke dalam golongan orang yang mendustakan agama. Allah SWT berfirman yang Artinya: Tahukah kamu (orang) yang mendustakan agama? (1) itulah orang yang menghardik anak yatim, (2) dan tidak menganjurkan memberi makan orang miskin, (3). (QS. al-Maun:13). Marxisme meniadakan kepemilikan harta dalam bentuk apapun. Semua harus jadi milik bersama, sedangkan dalam Islam tidak setuju dengan pendapat Marx .

${ }^{27}$ Ibid., 187.

28 A. G. Lugandi, PendidikaniOrang Dewasa (Sebuah Uraian Praktek, Untuk iPembimbing, Penatar, Pelatih idan iPenyuluh Lapangan), (Jakarta: iGramedia, i1989), 29.

${ }^{29}$ Samsul iMunir Amini, Ilmu iDakwah, 102.

${ }^{30}$ Abuddin iNata, dkki, Kajian iTematik Ali-iQuran tentang iKonstruksi Sosial, (Bandung: Angkasa Raya, 2008), 175 i. 
Ketika harta dimiliki bersama, tatanan kehidupan akan menjadi kacau. Semua boleh asal ambil. Tidak mempedulikan hak orang lain, karena memang tidak ada batas yang jelas antara hak individu dan hak bersama.

Adanya prinsip keadilan yang diwujudkan dengan prinsip pemerataan ekonomi yang adil ini ditegaskan oleh Ibn Hazm sebagaimana dikutip oleh Amien Rais didalam bukunya Tauhid Sosial mengatakan bahwa kalau ditengah masyarakat ada kelompok kaya dan miskin, sudah jadi kewajiban kelompok kaya tadi untuk melakukan proses pemerataan sosial ekonomi ke seluruh masyarakat. Dan menjadi hak kelompok orang-orang dibawah, miskin untuk mengambil haknya dari kelompok kaya. ${ }^{31}$ Prinsip tentang keadilan disini ditegaskan di dalam surat al-Hadid ayat 25 Artinya: Sungguh, kami telah mengutus rasul-rasul kami, dengan bukti-bukti yang nyata dan kami turunkan bersama mereka Kitab dan neraca (keadilan) agar manusia dapat berlaku adil. (QS. AlHadid: 25) dalam surat tersebut penegakan keadilan ekonomi dan penghapusan kesenjangan pendapatan menjadi salah satu misi utama para Nabi yang diutus oleh Allah SWT.

Dalam A1-Quran surat at-takatsur ayat 1-4 yang artinya: Bermegahmegahan telah melalaikan kamu. (1) sampai kamu masuk ke dalam kubur. (2) Sekali-kali tidak! Kelak kamu akan mengetahui (akibat perbuatanmu itu). (3) kemudian sekali-kali tidak! Kelak kamu akan mengetahui. (4) Dalam kutipan ayat Al-Quran tersebut sedikit menerangkan tentang kemegahan dan siksaan kubur bagi orang lalai dalam harta yang telah allah titipkan.

2. Ta'aruf

Pluralisme, dalam kamus besar Bahasa Indonesia diartikan keadaan masyarakat yang majemuk (bersangkutan dengan sistem sosial dan politiknya. ${ }^{32}$ Agama, diartikan sebagai sebagai sistem, prinsip kepercayaan kepada Tuhan (dewa dsb) dengan ajaran kebaktian dan kewajiban-kewajiban yang bertalian dengan kepercayaan itu. ${ }^{33}$ Perspektif, diartikan sebagai sudut pandang;

${ }^{31}$ M. Amien Rais, Tauhid Sosial; Formula Menggempur Kesenjangan, (Bandung: Mizan, 1998), 111.

32 Depertemen Pendidikan dan Kebudayaan, Pusat Pembinaan dan Pengembangan Bahasa, Kamus Besar Bahasa Indonesia, (Jakarta: Balai Pustaka, 1997) 777. edisi II, cet. 9.

${ }^{33}$ Ibid., 10. 
pandangan. ${ }^{34}$ Kehidupan, diartikan sebagai cara (keadaan, hal) hidup. Diantara arti hidupadalah masih terus ada, bergerak, dan bekerja sebagaimana mestinya dan mengalamikehidupan dalam keadaan atau keadaan tertentu. ${ }^{35}$ Beragama diartikan sebagai menganut agama; beribadat; taat kepada agama; baikhidupnya; sangat menmuja-muja dan gemar sekali kepada seseorang atau sesuatu. ${ }^{36}$

Dalam indentitas dan plurasm pada ajaran agama islam telah difirmankan dalam Al-Quran Surat Al-Baqorah Ayat 255-257 yang artinya: Allah, tidak ada Tuhan (yang berhak disembah) melainkan Dia Yang Hidup kekal lagi terus menerus mengurus (makhluk-Nya); tidak mengantuk dan tidak tidur. Kepunyaan-Nya apa yang di langit dan di bumi. Tiada yang dapat memberi syafa'at di sisi Allah tanpa izin-Nya? Allah mengetahui apa-apa yang di hadapan mereka dan di belakang mereka, dan mereka tidak mengetahui apa-apa dari ilmu Allah melainkan apa yang dikehendaki-Nya. Kursi Allah meliputi langit dan bumi. Dan Allah tidak merasa berat memelihara keduanya, dan Allah Maha Tinggi lagi Maha Besar. (ayat 255) Tidak ada paksaan untuk (memasuki) agama (Islam); sesungguhnya telah jelas jalan yang benar daripada jalan yang sesat. Karena itu barangsiapa yang ingkar kepada Thaghut dan beriman kepada Allah, maka sesungguhnya ia telah berpegang kepada buhul tali yang amat kuat yang tidak akan putus. Dan Allah Maha Mendengar lagi Maha Mengetahui . (ayat 256) Allah Pelindung orang-orang yang beriman; Dia mengeluarkan mereka dari kegelapan (kekafiran) kepada cahaya (iman). Dan orang-orang yang kafir, pelindung-pelindungnya ialah syaitan, yang mengeluarkan mereka daripada cahaya kepada kegelapan (kekafiran). Mereka itu adalah penghuni neraka; mereka kekal di dalamnya. (ayat 257).

Dalam hal ini Allah adalah Dzat yang tidak ada yang berhak dihadapkan padanya uluhiyah dan ubudiyah kecuali Dia, Yang Maha hidup yang mempunyai seluruh hakikat kehidupan yang sempurna, sesuai dengan keagungan Nya, lagi Maha mengatur segala sesuatu, tidak mengantuk dan tidak tidur, tidak ada paksaan dalam memeluk agama islam karena Islam adalah agama yang benar dan terang, sehingga tidak perlu ada paksaan kepada siapapun untuk memeluknya.

\footnotetext{
${ }^{34}$ Ibid., 760.

35 Ibid., 350.

${ }^{36}$ Ibid., 10
} 
Sudah terlihat jelas antara kebenaran dan kesesatan. Ulil Abshar Abdalla, salah satu dari kaum pluralis-liberalis mempunyaipendapat esensi dari kebenaran yang dikandung oleh semua agama adalah sama, meskipun terdapat perbedaan dalam segi ajaran dan syariat. Agama yang satu tidak bisa membatalkan agama yang lain, demikian pula syariat agama tertentu tidak bisamenghapuskan syariat dalam agama, lain, semata-mata karena agama tertentu datang lebih belakangan. ${ }^{37}$

Dalam konteks Islam mendefinisikan diri di tengah-tengah umat beragamalain; kaum pluralis memahami pluralisme sebenarnya lebih dari sekadar pengakuanakan kenyataan bahwa kita majemuk, melainkan juga terlibat aktif di dalam kemajemukan itu. ${ }^{38}$ Dalam Firman Allah pada Al-Quran Surat Yunus: 99, terjemahnya: "Dan jikalau Tuhanmu menghendaki, tentulah beriman semua orang yang di muka bumi seluruhnya. Maka apakah kamu (hendak) memaksa manusia supaya mereka menjadi orang-orang yang beriman semuanya?." jika Allah menghendaki seluruh penduduk bumi ini beriman, maka semuanya akan beriman. Dalam hal ini janganlah kita merasa sedih melihat kekufuran orangorang musyrik. Karena sesungguhnya, tidak ada keimanan kecuali atas dasar kesukarelaan hati. Senada dengan firman Allah lainnya yang terdapat pada Surat Kahfi:29, Surat Ar-Ra'd: 11 dan Surat Al-Hujarat :11-13.

\section{Ceramah}

Menurut A. G. Lugandi, menjelaskan bahwa ceramah agama adalah suatu penyampaian informasi yang bersifat searah, yakni dari ceramah kepada hadirin. ${ }^{39}$ Berbeda lagi dengan pendapat Abdul Kadir Mansyi, beliau berpendapat bahwa ceramah adalah metode yang dilakukan dengan cara atau maksud untuk menyampaikan keterangan petunjuk, pengertian, penjelasan tentang suatu masalah dihadapan orang banyak. ${ }^{40}$ Dalam Al-Quran Surat Yusuf: 108 yang artinya "Inilah jalan (agama) ku, aku dan orang-orang yang mengikutiku mengajak (kamu) kepada Allah dengan hujjah yang nyata, Maha Suci Allah, dan aku tiada termasuk orang-orang yang musyrik". Bahwa disini

${ }^{37}$ Ulil Abshar Abdalla, MenjadiiMuslimiLiberal, (Jakarta: Penerbit Nalar, 2005)

38 Nurcholis Madjidiet. al., Fikih Lintas Agama, (Jakarta: Penerbit Yayasan Wakaf Paramadina \& The Asia Foundation, 2004), 215.

${ }^{39}$ iA. Gi. Lugandi, Pendidikan Orang Dewasa (Sebuah Uraian Praktek, Untuk Pembimbing, Penatar, Pelatih dan PenyuluhiLapangan), (Jakarta: Gramedia, 1989), 29.

${ }^{40}$ Abdul Kadir Munsyi, Metode Diskusi Dalam Dakwah, (Surabaya: Al-Ikhlas, 1981), 33. 
diterangkan agar kita selalu dijalan Allah dan hujjah atau Yakni dengan bukti yang jelas dan pengetahuan tentang kebenarannya.

Pada firman Allah di Surat Al-An'am: 90 yang artinya "Mereka itulah orang-orang yang telah diberi petunjuk oleh Allah, maka ikutilah petunjuk mereka. Katakanlah: "Aku tidak meminta upah kepadamu dalam menyampaikan (Al-Quran)". Al-Quran itu tidak lain hanyalah peringatan untuk seluruh ummat." Pada ayat ini adalah sebuah seruan untuk agar manusia menyampaikan kebaikan dan suatu peringatan kepada ummat. Juga terdapat pada Al-Quran Surat An-Nahl: 125 yang artinya: “Ajaklah agama dengan tujuanmu dengan: cara yang bijaksana, nasehat yang baik, berdebat dengan cara yang baik”. Sabda Rasuallah SAW, Barang siapa diantara kamu melihat kemungkaran, maka hendaklah ia mengubahnya (mencegahnya) dengan: Tangannya (kekuasaannya) apabila ia tidak sanggup, Lidahnya (nasehat) apabila ia tidak kuasa maka dengan. Hatinya, dan itulah selemah-lemah iman. Adapun dalam metode dakwah dalam melaksanakan dakwah tercantum dalam surat Al-Qur'an Surat An-Nahl ayat 125, yang menunjukkan bahwa metode dakwah itu ada 3 cara yaitu: al-hikmah, al-maudzatil hasanah, al-mujadalah allati hiya ahsan. ${ }^{41}$ Dapat diartikan pula metode dakwah adalah cara-cara dakwah yang dipergunakan oleh seseorang da' $i$ untuk menyampaikan materi dakwah yaitu Islam atau serentetan kegiatan untuk mencapai kegiatan tertentu. ${ }^{42}$

\section{Studi Kasus}

Sejumlah Sesuai dengan observasi penulis Konsep dakwah bil hal dalam majelis taklim di masjid Al-Aminiyah Sudimara Pinang Kota Tangerang yang telah berlangsung sekitar 7 tahun yang diawali oleh murid Yayasan Al-Aminiyah, dalam yayasan tersebut para murid ada yang ikut kelas penghafal Al-Quran, Kelas alim(mempelajari tafsir dan hadits) berlangsungnya waktu warga setempat ada yang ikut belajar membaca Al-Quran serta Anaknya untuk belajar membaca dan menambah keilmuan dalam ibadah amalaiyah.${ }^{43}$ Dakwah adalah suatu usaha atau

\footnotetext{
${ }^{41}$ Hasanuddin, Hukum Dakwah: Tinjauan AspekiHukum DalamiBerdakwahiDi Indonesia, i (Jakarta: Pedoman iIlmu iJaya), 36.

${ }^{42}$ Moh. iAli Aziz, Ilmu iDakwah, (Jakarta: Perenada iMedia, 2004), iCet. Ke-1, 122.

${ }^{43}$ Observasi langsung di Masjid Al-Aminiyah Tangerang Kota, (Tanggal 19 November 
proses yang dilakukan dengan sadar dengan terencana untuk mengajak umat manusia kejalan Allah dengan mentrasformasikan nilai-nilai ajaran islam. ${ }^{44} \mathrm{Nabi}$ Muhammad SAW. adalah Nabi terakhir yang diutus oleh Allah SWT. Untuk mengeluarkan manusia dari kegelapan menuju alam yang terang benderang, menjadi penebar rahmat bagi sekalian alam dengan menjadikan perbaikan akhlak di segala bidang sebagai pogram andalan, dan membawa kabar gembira bagi umat yang menerima ajarannya serta peringatan bagi yang menolak. ${ }^{45}$ Berita gembira tersebut menggambarkan nilai-nilai kejadian manusia dan martabatnya diantara seluruh makhluk yang diciptakan Allah SWT. ${ }^{46}$

Siti Muru'ah dalam bukunya bukunya Motodelogi Dakwah Kontenporer menyatakan bahwa, dakwah bil hal adalah dakwah dengan perbuatan nyata, terbukti bahwa pertama kali Rasululah tiba di Madinah yang dilakukan adalah pembangunan Masjid Quba, mempersatukan kaum Anshar dan Muhajirin dalam ikatan ukhuwah Islamiayah dan seterusnya. ${ }^{47}$ Cara demikian bisa disampaikan dalam bentuk ceramah, khutbah, diskusi, dan sebagainya. ${ }^{48}$ Berpijak dari pengertian di atas dapat dikatakan bahwa dakwah bil-hal mempunyai peran dan kedudukan penting dalam dakwah bil-lisan. Dakwah bil-hal bukan bermaksud mengganti maupun menjadi perpanjangan dari dakwah bil-lisan, keduanya mempunyai peran penting dalam proses penyampaian ajaran Islam, hanya saja tetap dijaga isi dakwah yang disampaikan secara lisan itu harus seimbang dengan perbuatan nyata da'i. ${ }^{49}$

Menurut Aji Fauzan Pengurus Yayasan Al-Aminiyah Sejak tahun 2018 sampai dengan sekarang menerapkan jadwal yang berbeda untuk majelis taklim yang sebelumnya di terapkan pada hari senin dan jumat malam, dan sekarang di terapkan di hari senin sampai dengan jumat pukul 18.30 s.d 19.30 WIB. ${ }^{50}$ Menurut hemat penulis penerapan waktu yang telah dilaksanakan kurang efektif dikarenakan

${ }^{44}$ Asmuni Syukur, Dasar-Dasar Strategi Dakwah Islam, (Surabaya: Al-ikhlas, 1983), 21.

${ }^{45}$ Wahyu Ilaihi, Harjani Hefni, Pengantar Sejarah Dakwah, (Jakarta: Kencana, 2007), 36.

${ }^{46}$ Mohammad Nasir, Fiqhud Da'wah, (Jakarta: Media Dakwah, 2000), 3. 2000), 75

47 iDra Siti Muru'ah, Metodologi Dakwah Kontemporer, (Yogyakarta: Mitra Pustaka,

${ }^{48}$ Kustadi Suhandang, Ilmu Dakwah, Prespektif Komunikasi, 167.

49 SoetjiptoiWirosardjono, "Dakwah: Potensi dalam Kesenjangan" dalamiMajalah Pesantren, iNo. i4 iVol. iIV (iJakarta: iP3M, 1987), pi. 5.

${ }^{50}$ Wawancara langsung di Masjid Al-Aminiyah Tangerang Kota, (tanggal 03 Desember 2019, pukul 17.30 WIB) 
mengganggu jamaah untuk shalat isya' di awal waktu. Seperti Firman Allah pada Al-Quran Surat Maryam: 59 yang artinya "Dan datanglah orang-orang setelah mereka yang menyia-nyiakan shalat." Bahkwa jelas untuk umat Islam agar tidak menyia-nyiakan shalat ketika waktu yang telah ditentukan, Juga terdapat Dalam sebuah hadis yang shahih tentang keutamaan melaksanakan shalat pada awal waktu. Rasulullah bersabda:

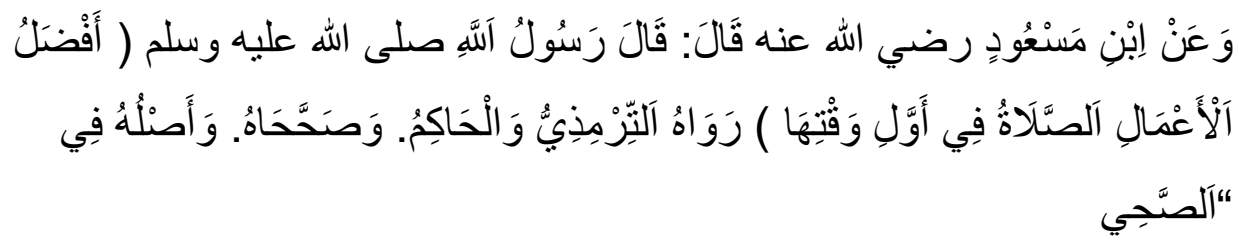

Dari Ibnu Mas'ud Radhiyallaahu 'anhu bahwa Rasulullah Shallallaahu 'alaihi wa Sallam bersabda: "Perbuatan yang paling mulia ialah shalat pada awal waktunya." Hadits riwayat dan shahih menurut Tirmidzi dan Hakim. Asalnya Bukhari-Muslim. ${ }^{51}$

Implikasi dari pernyataan Islam sebagai agama dakwah menuntut umatnya agar selalu menyampaikan dakwah, karena kegiatan ini merupakan aktifitas yang tidak pernah usai selama kehidupan dunia masih berlangsung dan akan terus melekat dalam situasi dan kondisi apapun bentuk dan coraknya. ${ }^{52}$ Dan bagaimana para jamaah majelis taklim ini ketika sudah mengikuti kajian tersebut, penulis juga sudah meminta keterangan kepada salah satu jamah yang bernama Bapak Aqmal, dia berkata setelah mengikuti kajian taklim yang sudah 3 tahun ini saya merasa ilmu dan ibadah amaliyah mulai naik serta saya sekarang lebih memahami bagamana dalam mengerjakan perintah-NYA dan sedikit tahu juga bagaimana menjalin komunikasi yang baik kepada sesama manusia yang lainnya. ${ }^{53}$ Menurut Bapak Haris jamaah Majelis taklim, dia berkata, ketika saya pertama mengikuti kajian majelis taklim ini saya cukup banyak menerima pengetahuan ibadah-ibadah amaliyah dan Alhamdulillah lantaran dari kajian ini dan berkat ilmu serta pengetahuan yang ada saya lebih tenang dalam beribadah,

51 Mustofa AB, https://ikaba.net/2018/05/13/hadits-ke-139-keutamaan-shalat-di-awalwaktu/ (Dalam ihal ini isudah ijelas iketika sudah imemasuki iwaktu shalat isebaiknya idilakukan diawal iwaktu).

${ }^{52}$ Munzir Supata, dan Harjani Hefni, Metode Dakwahi, (Jakarta: Prenada Media, 2003), 5.

53 Wawancara langsung dimasjid Al-Aminiyah Tangerang Kota, (tanggal 04 Desember 2019) 
tapi terkadang kajian majelis taklim ini terlalu panjang waktunya sehingga ketika akan shalat isya' jamaah harus mundur sekitar 20 menit dari waktu awal shalat isya' tersebut ${ }^{54}$. Munir berpendapat metode adalah cara atau jalan yang harus dilalui untuk mencapai tujuan. ${ }^{55}$

Dakwah bi al-hal yaitu dakwah dengan perbuatan nyata yang meliputi keteladanan. Misalnya dengan tindakan amal karya nyata yang dari karya nyata tersebut hasilnya dapat dirasakan secara konkret oleh masyarakat sebagai objek dakwah. ${ }^{56}$ Orang yang pandai mendengar atau pendengar yang baik disebut oleh al-Qur'an sebagai orang yang memiliki udzunun wa'iyah (Q.S. al-Haaqah [69]: 12) atau telinga yang fungsional. ${ }^{57}$ Sebagaimana tercantum dalam QS. Al-Isra': 105.

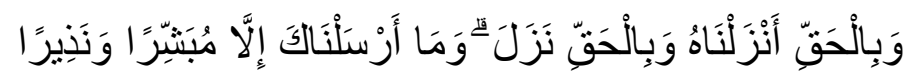

Artinya: "Dan Kami turunkan (Al Quran) itu dengan sebenar-benarnya dan Al Quran itu telah turun dengan (membawa) kebenaran. Dan Kami tidak mengutus kamu, melainkan sebagai pembawa berita gembira dan pemberi peringatan"

Dengan ayat di atas, bagaimanapun dalam berdakwah, da'i tidak hanya terpatok pada satu metode saja, banyak metode yang digunakan dalam berdakwah, tergantung pada beberapa hal, misalnya tujuan, sasaran dakwah, situasi dan kondisi, media dan fasilitas yang tersedia, kepribadian dan kemampuan seorang da'i. ${ }^{58}$ Yang sebenarnya, dakwah bil haal ini bersumber pada ajaran Islam yang dicontohkan langsung oleh Rasulullah SAW dan para sahabatnya, sehingga umur Islam yang seharusnya menjadi pelopor pelaksanaan dakwah ini. Tanpa pengabaian dakwah bil lisan, maka dakwah bil haal seharusnya menjadi perioritas utama, sekaligus usaha preventif bagi umat Islam (di pelosok desa) agar tidak pindah agama. ${ }^{59}$

${ }^{54}$ Wawancara langsung dimasjid Al-Aminiyah Tangerang Kota, (tanggal 04 Desember

${ }^{55}$ Munir, metode dakwah, (Jakarta: kencana 2009), 6.

${ }^{56}$ Samsul iMunir iAmin, illmu Dakwah, (Jakarta: iAmzah, i2009), 11.

57 Waryono Abdul Ghafur, Strategi Qur'ani MengenaliiDiriiSendiri dan Meraih iKebahagiaan iHidup (Yogyakarta: Belukar, 2004), 107.

${ }^{58}$ Asmuni Syukir, Dasar-Dasar Strategi Dakwah Islam (Surabaya: Al-ilkhlas, 1983), 103 i.

${ }^{59}$ Hamka, Prinsip dan Kebijakan Dakwah Islam, (Jakarta: Pustaka, 1981), 159. 


\section{Analisis}

Penulis menganalisis Konsep dakwah bil hal dalam majelis taqlim di masjid al-aminiyah sudimara pinang kota tangerang. Dalam melakukan analisis tersebut penulis menggunakan tiga aspek Post-Marxism, Identity politics and critical pluralism, Dan Discourses. Metode yang nantinya untuk menjawab tiga pertanyaan minor yaitu bagaimana histori yang mempengaruhi jamaah tersebut terhalang melaksanakan shalat isya' diawal waktu. Kedua, apa yang mendasari tujuan identitas politik dan pluralism dalam majelis taqlim tersebut. Ketiga, bagaimana pandangan serta efek dari discourses atau ceramah tersebut kepada para jamaah.

Pada Metode Post-Marxism yang bercerita bagaimana menjawab histori atau sejarah yang memperngaruhi para jamaah terhalang dalam melaksanakan shalat isya' diawal waktu. Dalam hal ini karena adanya perubahan jam pelaksanaan majelis taklim yang sebelumnya dilakukan pada pukul 18.30 s.d 19.15 WIB dan digantikan pukul 18.30 s.d 19.30 WIB sehingga shalat isya' berjamaah yang semestinya dilaksanakan pukul 19.08 WIB mundur sampai 19.30 WIB. Karena dalam Al-Quran terdapat beberapa yang benar satunya:

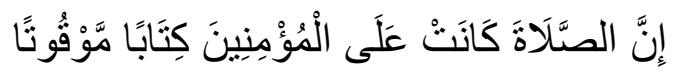

"Sesungguhnya shalat memiliki waktu yang telah ditetapkan bagi orang beriman." (QS. An Nisaa': 103)

Juga dalam Al-Quran Surat Maryam: 59.

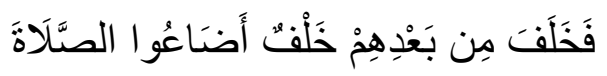

"Dan datanglah orang-orang setelah mereka yang menyia-nyiakan shalat."

Dalam hal tersebut jelas untuk tidak menyia-nyiakan waktu shalat, Shalat merupakan ibadah yang wajib untuk didirikan oleh setiap umat muslim. Di dalam Hadist Riwayat Thabrany disebutkan bahwa Rasulullah saw bersabda amalan yang pertama kali dihisab dari seorang hamba pada hari kiamat adalah 
shalatnya. ${ }^{60}$ Shalat juga merupakan kewajiban yang dititahkan Allah Swt kepada Rasulullah saw dan para pengikutnya untuk memerintahkan keluarga mereka supaya melaksanakannya. Mengingat pentingnya melaksanakan shalat, wajib hukumnya mengganti shalat yang terlewatkan sebab tertidur atau lupa. ${ }^{61} \mathrm{Hal}$ ini menandakan betapa ibadah shalat merupakan ibadah utama yang membedakan apakah seseorang benar-benar Islam atau tidak. ${ }^{62}$ Ar-Rumi berpendapat yang dimaksud dengan semangat melaksanakan shalat fardlu adalah bahwa Allah telah mewajibkan atas hamba-Nya menunaikan shalat dan mewajibkan atas mereka menunaikan tepat pada waktu yang telah ditentukan. Seseorang tidak boleh mengerjakan shalat fardlu selain pada waktu yang telah ditentukan, kecuali bila ada alasan tertentu yang telah disyariatkan. Misalnya ketiduran, lupa dan sebagainya. ${ }^{63}$

Dalam sejarah islam sendiri, yang merupakan perintah pertama dalam Islam melalui Surah Al-Alaq ayat 1-5, yang artinya: "bacalah dengan (menyebut) nama Tuhanmu Yang menciptakan, Dia telah menciptakan manusia dari segumpal darah, Bacalah, dan Tuhanmulah Yang Maha Pemurah, Yang mengajar (manusia) dengan perantaran kalam, Dia mengajar kepada manusia apa yang tidak diketahuinya." Dalam Firman Allah tersebut, maka permulaan yang diturukan dari al-quran ini merupakan ayat-ayat penuh kemulian dan keberkahan yaitu Rahmat Allah yang pertama kali diberikan kepada hamba, nikmat Allah yang pertama kali diberikan kepada mereka dimana terdapat peringatan atas permulaan penciptaan manusia dari segumpal darah, dan sesungguhnya diantara kemulian yang Allah yaitu mengajarkan kepada manusia apa yang tidak tahu, lalu mengagungkannya dan memuliakannya dengan ilmu dan itu adalah takdir yang menjadikan sebaik-baik makhluk Adam a.s atas mempunyai kelebihan atas malaikat. Dalam sejarah penciptaan ini terkadang, ilmu berada di dalam akal fikiran, terkadang berada dalam lisan dan terkadang

${ }^{60}$ Drai. iNeni Nuraeni, M. Agi, Tuntunan Shalat iLengkap idan Benar, (Yogyakarta: iMutiara Media, 2008i), 8.

${ }^{61}$ iAhmad Rofi iUsmani, iNikmatnya iShalat: iKisah iPara Pencari, i (Bandung: iMizania, i2015i), 50 .

${ }^{62}$ Nur Laela Isnawati, Sepuluh Amal Shalih Yang Membuat Tubuh Selalu Sehat, (Yogyakarta: Sabil, 2013) 63.

${ }^{63}$ Nahd bin Abdurrahman bin Sulaiman Ari-iRumi, Pemahaman SalatidalamiAl-Qur'an, iPenterjemahiDeden Suhendar, (Bandung: Sinar Baru Algesindo, 1994), 123. 
dalam tulisan tangan. Akal, lisan, dan tulisan, dan tulisan mengharuskan keduanya (dalam perolehan ilmu) dan tidak sebaliknya.

Penjelasan-penjelasan al-Qur'an dan al-Hadits di atas menunjukkan bahwa paradigma ilmu dalam Islam adalah teosentris. Karena itu, hubungan antara ilmu dan agama memperlihatkan relasi yang harmonis, ilmu tumbuh dan berkembang berjalan seiring dengan agama. Karena itu, dalam sejarah peradaban Islam, ulama hidup rukun berdampingan dengan para ilmuwan. Bahkan banyak ditemukan para ilmuwan dalam Islam sekaligus sebagai ulama. Misalnya, Ibn Rusyd di samping sebagai ahli hukum Islam pengarang kitab Bidayah alMujtahid, juga seorang ahli kedokteran penyusun kitab al-Kulliyat fi alThibb. ${ }^{64}$

Pada metode Identity politics and critical pluralism, dalam identitasnya sendiri islam yang bertumpu pada Al-Quran Surat Asy-Syura: 13 yang artinya: "Dia telah mensyari'atkan bagi kamu tentang agama apa yang telah diwasiatkanNya kepada Nuh dan apa yang telah Kami wahyukan kepadamu dan apa yang telah Kami wasiatkan kepada Ibrahim, Musa dan Isa yaitu: Tegakkanlah agama dan janganlah kamu berpecah belah tentangnya. Amat berat bagi orang-orang musyrik agama yang kamu seru mereka kepadanya. Allah menarik kepada agama itu orang yang dikehendaki-Nya dan memberi petunjuk kepada (agama)- Nya orang yang kembali (kepada-Nya)". Amat berat bagi orang-orang musyrik agama yang kamu seru mereka kepadanya. Allah menarik kepadanya agama itu orang yang dikehendaki-Nya dan memberi petunjuk kepada (agama)- Nya orang yang kembali.” Dalam Firman tersebut Allah SWT menjelaskan bagi Umat Nabi Muhammad SAW tentang agama Islam sebagai identitas yang melekat pada setiap umat nabi Muhammad SAW yang seterusnya umat islam agar selalu bertauhid dan keimanan kepada Allah SWT serta ketaatan kepada rosul-rosulnya juga syariat islam itu sendiri. Akan menjadi penting terkait Pendidikan, ${ }^{65}$ yang bisa membuat umat islam semakin mengetahui identitas dan keberagaman dalam bersosial. Sikap hidup beragama yang berlangsung di masyarakat, tiada lain merupakan tindakan

${ }^{64}$ Mohammad Kosim, "ILMU PENGETAHUAN DALAM ISLAM" (Perspektif FilosofisHistoris)", Jurnal Tadrîs. Volume 3. Nomor 2. 2008. hal, 124.

65 Al-Syaibany, mengemukakan bahwa tujuan tertinggi pendidikan Islam adalah mempersiapkan kehidupan dunia dan akhirat., Omar Muhammad Al-Thoumy Al-Syaibani, Falsafah Pendidikan Islam, (Jakarta: Bulan Bintang, 1979), hal. 410. 
sosial keagamaan yang diekspresikan oleh para pemeluk agama sebagai bentuk dan perwujudan kepercayaan agama. ${ }^{66}$

Sebagaimana dikatakan oleh Alwi Shihab dalam Islam Inklusif, bahwa umat beragama dihadapkan kepada serangkaian tantangan baru yang tidak terlalu berbeda dengan apa yang pernah dialami sebelumnya. Pluralisme agama, konflik intern atau antar agama adalah fenomena nyata ${ }^{67}$ Pluralisme agama dalam hal ini, harus benarbenar dapat dimaknai sesuai dengan akar kata serta makna sebenarnya. Hal itu merupakan upaya penyatuan persepsi untuk menyamakan pokok bahasan sehingga tidak akan terjadi misinterpretation maupun misunderstanding. Menurut Alwi Shihab, pengertian pluralisme dapat disimpulkan menjadi 3 yaitu: pertama, pluralisme tidak semata menunjuk pada kenyataan tentang adanya kemajemukan. Namun yang dimaksud pluralisme adalah keterlibatan aktif terhadap kenyataan kemajemukan tersebut. Kedua, pluralisme harus dibedakan dengan kosmopolitanisme. Dalam hal ini Kosmopolitanisme menunjuk suatu realitas di mana aneka ragam ras dan bangsa hidup berdampingan di suatu lokasi. Maksudnya walaupun suatu ras dan bangsa tersebut hidup berdampingan tetapi tidak ada interksi sosial. Ketiga, konsep pluralisme tidak dapat disamakan dengan relativisme. Paham relativisme menganggap "semua agama adalah sama”. Keempat, pluralisme agama bukanlah sinkretisme, yakni menciptakan suatuagama baru dengan memadukan unsur tertentu atau sebagian komponen ajaran dari beberapa agama untuk dijadikan bagian integral dari agama tersebut. ${ }^{68}$ Setelah mengetahui definisi pluralism tersebut, maka penulis dapat mengartikan pluralisme agama adalah suatu sikap membangun tidak saja kesadaran normatif teologis tetapi juga kesadaran sosial, di mana kita hidup di tengah masyarakat yang plural dari segi agama, budaya, etnis, dan berbagai keragaman sosial lainnya. Karena, pada dasarnya Islam mengajarkan faham kemajemukan keagamaan (religious pluralit), Islam memiliki

66 Website uinsgd.ac.id "https://uinsgd.ac.id/berita/pluralisme-dan-titik-temu-agamaagama/", (diakses tanggal 15 Desember 2019 pukul 00.41 WIB)

${ }^{67}$ Alwi Shihab, Islam Inklusif Menuju Sikap Terbuka, (Bandung: Mizan, 1999), 39.

${ }^{68}$ Ibid., 41-42. 
sikap yang unik dalam hubungan antaragama, yakni toleransi, kebebasan, keterbukaan, kewajaran, keadilan dan kejujuran. ${ }^{69}$

Pengakuan Al-Qur'an terhadap pemeluk agama-agama lain, antara lain tercantum dalam QS. Al-Baqarah: 62 yang artinya: "Sesungguhnya orang-orang mukmin, orang-orang Yahudi, orang-orang Nasrani dan orang-orang Shabi'in, siapa saja diantara mereka yang benar-benar beriman kepada Allah, hari kemudian dan beramal shaleh, mereka akan menerima pahala dari Tuhan mereka, tidak ada pula kekhawatiran kepada mereka, dan tidak (pula) mereka bersedih hati.", dalam firman Allah SWT tersebut menjelaskan bahwa sebelum nabi Muhammad SAW diutus sebagai penutup para nabi dan rasul kepada seluruh umat manusia, bahwa ada orang-orang sebelum nabi Muhammad SAW yang benar beriman kepada Allah SWT maka mereka akan menerima pahala yang utuh di hari pembalasan kelak diakherat. Dengan firman-NYA itulah pengakuan Allah terhadap eksistensi agama-agama yang ada di muka bumi dengan tidak membedakan kelompok, ras, dan bangsa, sangatlah jelas.

Sedangkan dalam metode discourses atau yang berati ceramah, metode dakwah ini lebih dikenal dengan approach, atau cara yang dilakukan oleh seorang da'i atau komunikator. ${ }^{70}$ suatu tekhnik atau metode dakwah ini banyak diwarnai oleh ciri karakteristik bicara oleh seseorang da'i/mubaligh pada suatu aktivitas dakwah. Sebagaimana firman-Nya berikut yang artinya: "perkataan yang baik dan pemberian maaf lebih baik dari sedekah yang diiringi dengan sesuatu yang menyakitkan (perasaan si penerima). Allah Maha Kaya lagi Maha Penyantun.” (Q.S Al-Baqorah: 263), berkomunikasi yang baik sebagaimana dijelaskan ayat tersebut merupakan bagaimana seseorang melakukan penolakan dengan cara tidak sampai menyakitkan hati maupun perasaan si penerima. Proses adalah urutan pelaksanaan atau kejadian yang terjadi secara alami didesain, mungkin menggunakan waktu, ruang, keahlian atau sumber daya lainnya, yang menghasilkan suatu hasil. Suatu proses mungkin dikenali oleh perubahan yang diciptakan terhadap sifat-sifat dari satu atau lebih objek di bawah pengaruhnya. ${ }^{71}$ 77.

${ }^{69}$ Fathimah Usman, Wahdat al-Adyan Dialog Pluralisme Agama, (Yogyakarta: LkiS, 2002),

70 Toto Tasmara, Komunikasi Dakwah, (Jakarta; Gaya Media Pratama,1997), 43.

71 https://.m.wikipedia.org/wiki/proses., (diakses tanggal 15 Desember 2019 pukul 02.01 WIB) 
Ceramah adalah suatu tehnik metode dakwah yang banyak diwarnai oleh karkteristik bicara oleh seorang da'i/mubaligh pada suatu aktivitas dakwah. Ceramah dapat pula bersifat propaganda, kampanye, berpidato (rhetorika), khutbah, sambutan, mengajar dan sebagainya. ${ }^{72}$ Dalam penyampaian dakwah menggunakan ceramah langsung ini berupaya menggunakan kata-kata yang baik. Baik disini bukan hanya tepat retorika yang digunakan, lebih dari itu katakatanya bukan dibuat-buat agar jama'ah terpikat. Namun materi pada kitabnya juga harus tersampaikan dan ada dasarnya. ${ }^{73}$ Bapak Rohimah selaku Pembina dan juga Da’i di Majelis Taklim masjid Al-Aminiyah menyatakan bahwa, meskipun da'i-da'I yang rutin mengisi dan menyampaikan materi pada jama'ah Majelis Taklim masjid Al-Aminiyah adalah da'i setempat, jama'ah tidak merasa bosan, karena para da'i dalam menyampaikan materi dakwahnya sangat berhatihati serta memiliki kejelasan yang sesuai dengan kitab yang dibacakan. ${ }^{74}$

\section{KESIMPULAN}

Dari uraian yang telah dipaparkan diatas, dapat di kemukakan hal-hal berikut: pertama, Islam adalah agama dakwah, artinya agama yang menugaskan umatnya untuk menyebarkan dan mensyiarkan Islam kepada seluruh umat manusia baik dalam keadaan bagaimanapun dan dimanapun dakwah agama meniscayakan dilakukan secara individu, bersama maupun terorganisir dengan melibatkan berbagai komponen pemangku kepentingan masyarakat, dakwah agama bukan untuk "memasukkan" dan "mengeluarkan" manusia, tapi untuk menyatukan manusia secara sosial dan atau mewujudkan masyarakat yang baik dan bermartabat (khairo ummah) oleh karena itu implikasi dari pernyataan Islam sebagai agama dakwah menuntut umatnya agar selalu menyampaikan dakwah, karena kegiatan ini merupakan aktifitas yang tidak pernah usai selama kehidupan dunia masih berlangsung dan akan terus melekat dalam situasi dan kondisi apapun bentuk dan coraknya. Kedua, dalam hal ibadah yang bersifat kewajiban dan hal yang sifat sunnah harus mendahulukan kewajiban terhadap ibadah yang wajib

\footnotetext{
${ }^{72}$ Asmuni Syukir, Op, Cit, hal. 104.

${ }^{73}$ Observasi langsung pada majelis taklim masjid Al-Aminiyah, (tanggal 3 Desember 2019 pukul 18.22 WIB)

${ }^{74}$ Observasi langsung pada majelis taklim masjid Al-Aminiyah, (tanggal 3 Desember 2019 pukul 19.00 WIB)
} 
sesuai firman Allah "Sesungguhnya shalat memiliki waktu yang telah ditetapkan bagi orang beriman." (QS. An Nisaa': 103). Dalam hal tersebut jelas untuk tidak menyia-nyiakan waktu shalat, Shalat merupakan ibadah yang wajib untuk didirikan oleh setiap umat muslim. Ketiga, da'i atau muballigh bukan sekadar kuat dalam pengetahuan tapi juga memiliki kecerdasan kultural, Kegiatan pengembangan masyarakat bisa melalui dakwah bil hal yang terdiri dari kegiatan pokok berupa transformasi dan pelembagaan ajaran Islam ke dalam realitas Islam atau ibadah amaliyah.

Sesuai dengan firman Allah yang artinya: "Kamu adalah umat yang terbaik yang dilahirkan untuk manusia, menyuruh kepada yang ma'ruf, dan mencegah dari yang munkar" (Q. S. Ali Imran: 110). Amar ma'ruf nahi munkar tidak dapat dipisahkan, karena dengan amar ma'ruf saja tanpa nahi munkar akan kurang bermanfaat, bahkan akan menyulitkan amar ma"eruf yang pada gilirannya akan menjadi tidak berfungsi lagi apabila tidak diikuti dengan nahi munkar, dan mari untuk mencari ilmu dan meningkatkan amal ibadah guna menuju manusia yang bermanfaat.

\section{DAFTAR PUSTAKA}

\section{Buku \& Jurnal}

Abdullah, Ilmu Dakwah, kajian ontologi, epistimologi, aksiologi dan aplikasi dakwah, Depok: Raja Grapindo Persada, 2018.

Abdalla, Ulil Abshar. Menjadi Muslim Liberal, Jakarta: Penerbit Nalar, 2005.

Adi Sasono. Saifuddin, DKK, Solusi Islam atas Problematika Ummat, Jakarta: Gema Insani Press, 1998.

Alhadharah, "Dakwah Bil-Hal: Prospek Dan Tantangan Da'I" Jurnal Ilmu Dakwah Vol. 14 No.27, 2015.

Anonim, Pedoman Pembinaan Majelis Taklim, Jakarta: Dirjen Bimas Islam dan Urusan Haji proyek Peningkatan Tenaga Keagamaan, 1995.

Ali Moh. Aziz, Ilmu Dakwah, Cet. Ke-1 (Jakartai: Perenada Mediai, 2004).

Arifin M., Psikologi Dakwah Suatu Pengantar Studi, Jakarta: Bumi Aksara, 2000.

Asmuni, Syukir. Dasar-Dasar Strategi Dakwah Islam, Surabaya: Al-Ikhlas, 1983.

Asy-Syuwaikh. Adil Abdullah al-Laili, Bersama Kereta Dakwah, Sukses Berdakwah di Era Keterbukaan, Jakarta: Rabbani Press, 2006. 
Bin Nahd Abdurrahman bin Sulaiman Ar-Rumii, Pemahaman Salat dalam AlQur'an, Penterjemah Deden Suhendari, (Bandung: Sinar Baru Algesindo, 1994).

Bin Said Ali bin wahf ali-Qahtani, 9 Pilar Keberhasilan Da ’i Di Medan Dakwah, Diterjemahkan; Muzaid Hazbullah, Solo; Pustaka Arafah, 2001.

Depertemen Pendidikan dan Kebudayaan, Pusat Pembinaan dan Pengembangan Bahasai, Kamus Besar Bahasa Indonesia, Jakarta: Balai Pustaka, 1997.

Gill Branston With Roy Stafford, “The Media Student's Fifth Edition" USA And CANADA, 2010.

G. A Lugandi, Pendidikan Orang Dewasa (Sebuah Uraian Praktek, Untuk Pembimbing, Penatar, Pelatih dan Penyuluh Lapangan), Jakarta: Gramedia, 1989.

H. Siregar. Imran dan Shofiuddin, Pendidikan Agama Luar Sekolah (Studi Tentang Majelis Taklim), Jakarta: 2003.

Hasan Noorhaidi, Laskar Jihad, Islam, Militancy, and the Quest for Identity in PostNew Order Indonesia, (Ithaca, New York: Cornell University, 2006), terjemahan Laskar Jihad Jakarta: LP3ES, 2008.

Hasanuddin, Hukum Dakwah: Tinjauan Aspek Hukum Dalam Berdakwah Di Indonesia, Jakarta: Pedoman Ilmu Jaya, 1996.

Hamka, Prinsip dan Kebijakan Dakwah Islam, Jakarta: Pustaka, 1981.

Jurdi, Syarifuddin. “Gerakan Sosial Islam” Jurnal Politik Profetik Vol. 1 No. 1, 2013.

Kadir, Abdul Munsyi. Metode Diskusi Dalam Dakwah, Surabaya: Al-Ikhlas, 1981.

Khoirul, Ahmad Fata. "Diskursus dan Kritik Terhadap Teologi Pluralisme Agama" Jurnal MIQOT Vol. XLII No. 1, 2018.

Kuntowijoyo, Muslim Tanpa Masjid, Bandung: Mizan, 2001.

Mohammadi, Kosim. "ILMU PENGETAHUAN DALAM ISLAM (Perspektif Filosofis-Historisi)”, Jurnal Tadrîs. Volume 3. Nomor 2. 2008.

Munzir Supata, dan Harjani Hefni, Metode Dakwah, Jakarta: Prenada Media, 2003.

Munir, Samsul Amin. Ilmu Dakwah, Jakarta: Amzah, 2009.

Mudjab, Ahmad Mahalli. Buku Pintar Da'i, Surabaya: Duta Ilmu, 2005.

Munir M., Wahyu Ilaihi. Manajemen Dakwah, Jakarta: Kencana, 2006.

Muru'ah, Siti. Metodologi Dakwah Kontemporer. Yogyakarta: Mitra Pustaka, 2000. 
Munir, Metode Dakwah, Jakarta: kencana 2009.

Natsir M., “Fungsi Dakwah Perjuangan” Dalam Abdul Munir Mulkhan, Ideologis Gerakan Dakwah, Yogyakarta: Sipres, 1996.

Nata Abuddin, dkk, Kajian Tematik Al-Quran tentang Konstruksi Sosial, Bandung: Angkasa Raya, 2008.

Nasir Mohammad, Fiqhud Da 'wah, Jakarta: Media Dakwah, 2000.

Neni Dra. Nuraenii, M. Agi, Tuntunan Shalat Lengkap dan Benar, Yogyakarta: Mutiara Media, 2008.

Nur Isnawati, Laela. Sepuluh Amal Shalih Yang Membuat Tubuh Selalu Sehat, Yogyakarta, 2013.

Nurcholis Madjid et. al., Fikih Lintas Agama, Jakarta: Penerbit Yayasan Wakaf Paramadina \& The Asia Foundation, 2004.

Rais, M. Amien. Tauhid Sosial; Formula Menggempur Kesenjangan, Bandung: Mizan, 1998.

Supata Munzir, dan Harjani Hefni, Metode Dakwah, Jakarta: Prenada Media, 2003.

Safei Agus dan Nanih Machendrawaty, Pengembangan Masyarakat Islam, Bandung: 2001.

Siti Dra Muru'ah, Metodologi Dakwah Kontemporer. Yogyakarta: Mitra Pustaka, 2000.

Suhandang Kustadi, Ilmu Dakwah, Prespektif Komunikasi, Bandung: Remaja Rosdakarya, 2013.

Soetjipto Wirosardjono, "Dakwah: Potensi dalam Kesenjangan" dalam Majalah Pesantren, No. 4 Vol. IV. Jakarta: P3M, 1987.

Toto, Tasmara. Komunikasi Dakwah, Jakarta; Gaya Media Pratama, 1997.

Usman, Fathimah. Wahdat al-Adyan Dialog Pluralisme Agama, Yogyakarta: LkiS, 2002.

Warson Ahmad Munawir, AL-Munawir Kamus Bahasa Indonesia Cet. 4; Yogyakarta: Pustaka Progresif, 2008.

Wahyu Ilaihi, Harjani Hefni, Pengantar Sejarah Dakwahi, Jakarta: Kencana, 2007.

Waryono Ghafur, Abdul. Strategi Qur'ani Mengenali Diri Sendiri dan Meraih Kebahagiaan Hidupi, Yogyakarta: Belukar, 2004.

\section{Web \& Wawancara}

Chairul M Basrun Umanailo, "AGAMA DALAM IDENTITAS" https://www.researchgate.net/publication/ 323943107 AGAMA_DALAM_IDENTITAS (diakses pada 30 November 2019, pukul 13.55 WIB) 
Mustofa AB， https://ikaba.net/2018/05/13/hadits-ke-139-keutamaan-shalat-diawal-waktu/ (diakses tanggal 15 desember 2019)

Metode Dakwah Bil Hikmah dan Bil Hal. BAB I", dalam tanjung bunut.blogspot.com/metode-dakwah-bil-hikmah-dan-bil-hal. (05, April 2017)

Https://.m.wikipedia.org/wiki/proses., (diakses tanggal 15 Desember 2019 pukul 02.01 WIB)

Website uinsgd.ac.id "https://uinsgd.ac.id/berita/pluralisme-dan-titik-temu-agamaagama/"., (diakses tanggal 15 Desember 2019 pukul 00.41 WIB)

Observasi langsung pada majelis taklim masjid Al-Aminiyah, (tanggal 3 Desember 2019 pukul 19.00 WIB)

Observasi langsung di Masjid Al-Aminiyah Tangerang Kota, (Tanggal 19 November 2019)

Observasi langsung pada Majelis taklim masjid Al-Aminiyah, (tanggal 3 Desember 2019 pukul 18.22 WIB)

Wawancara langsung di Masjid Al-Aminiyah Tangerang Kota, (tanggal 03 Desember 2019, pukul 17.30 WIB)

Wawancara langsung di Masjid Al-Aminiyah Tangerang Kota, (tanggal 04 Desember 2019)

Wawancara langsung di Masjid Al-Aminiyah Tangerang Kota, (tanggal 04 Desember 2019) 
Khaisar Masrul \& Ahmad Saiful Bahri, Konsep Dakwah Bil Hal Dalam Majelis Taklim Di Masjid Al Aminiyah Sudimara Pinang Kota Tangerang | 166 